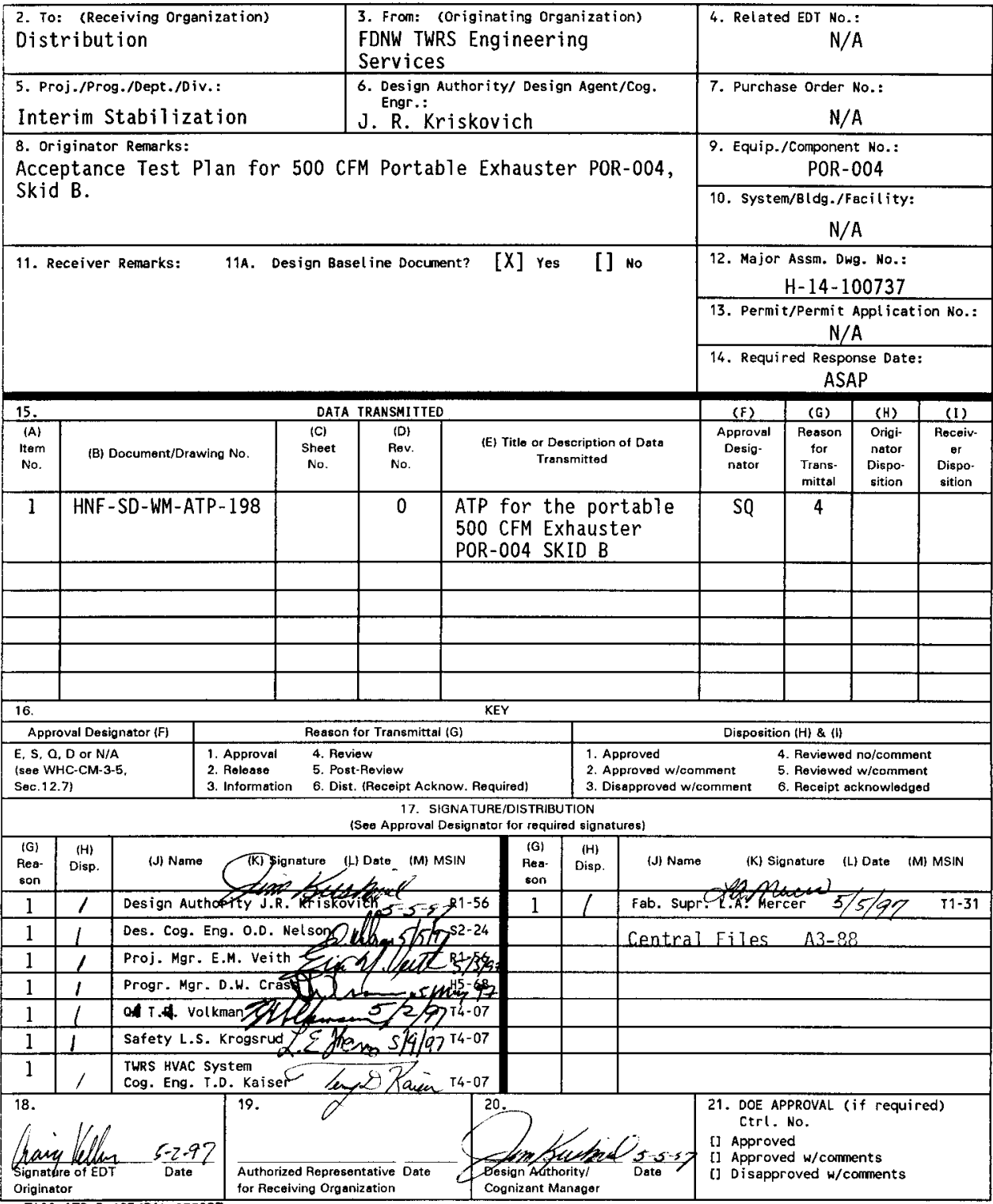




\title{
ATP FOR THE PORTABLE 500 CFM EXHAUSTER POR-004 SKID B
}

\author{
Craig M. Keller
}

Fluor-Daniel Northwest, Richland, WA 99352

U.S. Department of Energy Contract DE-AC06-96RL13200

\author{
EDT/ECN: $161453 / 53623$ UC: 2030 \\ Org Code: 04E00 ${ }^{4 N}$ Charge Code: C13697 \\ B\&R Code: EW3120072 Total Pages: 97
}

Key Words: Portable Exhauster, Saltwell Pumping, Waste Tank Ventilation, Flammable Gas Mitigation

Abstract: This Acceptance Test P1an is for a 500 CFM Portable Exhauster POR-004 to be used for saltwell pumping. The Portable Exhauster System will be utilized to eliminate potential flammable gases that may exist within the dome space of the tank. This Acceptance Plan will test and verify that the exhauster meets the specified design criteria, safety requirements, operations requirements, and will provide a record of the functional test results.

TRADEMARK DISCLAIMER. Reference herein to any specific comercial product, process, or service by trade name, trademark, manufacturer, or otherwise, does not necessarily constitute or imply its endorsement, recommendation, or favoring by the United States Governnent or any agency thereof or its contractors or subcontractors.

Printed in the United States of America. To obtain copies of this document, contact: Document Control Services, P.O. Box 950, Mailstop H6-08, Richland WA 99352, Phone (509) 372-2420; Fax (509) 376-4989.
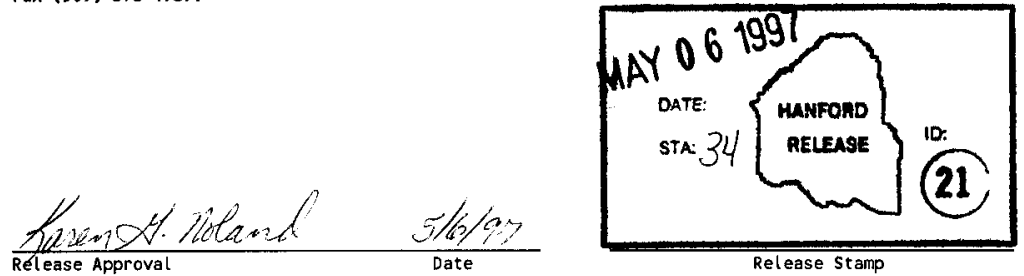

Approved for Public Release 


\section{TANK FARM}

\section{ACCEPTANCE TEST PROCEDURE}

\section{SYSTEM}

INTERIM STABILIZATION

ATP FOR THE PORTABLE 500 CFM EXHAUSTER, POR-004, SKID B

\section{CONTINUOUS USE}




\section{TANK FARM ACCEPTANCE TEST PROCEDURE}

\subsection{POWER SYSTEM CHECK (Cont inued)}

5.2.8 VERIFY Seal Pot Pump Control Selector Switch VTP-HS-101 (located on door of Exhauster Control Cabinet VTP-CP-105) is in the AUT0 position.

5.2.9 VERIFY CAB HEAT/COOL Selector Switch VTP-SS-105 (Located on door of Control Cabinet VTP-CP-105) is in OFF position.

5.2.10 VERIFY CAB HEAT/COOL Selector Switch VTP-SS-104 (Located on door of Heat Trace Cabinet VTP-ENCL-104) is in OFF position.

5.2.11 INSTALL Personal Locking Device on Main 480V Disconnect Switch VTP-DS- 101.

5.2.12 DISCONNECT Exhauster fan motor circuit from the Variable Frequency Drive (VTP-VFD-001) terminals T1, T2 and T3.

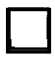

\section{CAUTION}

Do not apply Megger voltage to the Variable Frequency Drive VTP-VFD-001. Damage to the drive may result.

5.2.13 USING A lo00V Megger, megger between T1, T2 and T3 1eads to ground to ENSURE there is NOT a short between the exhauster fan motor windings and ground.

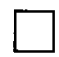

5.2.14 RECONNECT Exhauster fan motor circuit to the Variable Frequency Drive (VTP-VFD-001) terminals T1, T2 and T3.

5.2.15 USING a $1000 \mathrm{~V}$ Megger, megger test at the Heater Contactor VTP-CON206 load side (10cated at Heat Trace Cabinet VTP-ENCL-104), ENSURE there is NOT a short between Heater circuits and the Heater housing. 


\section{TANK FARM ACCEPTANCE TEST PROCEDURE}

\subsection{POWER SYSTEM CHECK (Continued)}

5.2.61 POSITION the Heat Trace cabinet selector switch "CAB HEAT/COOL" VTP-HS-104 to "Winter".

5.2.62 VERIFY the following:

- Heat Trace Cabinet Cooling Fan VTP-F-104 is OFF.

- Intrinsic Barrier Cabinet Cooling Fan VTP-F-106 is OFF.

- Heat Trace Cabinet Heater VTP-HTR-104 is ON.

- Intrinsic Barrier Cabinet Heater VTP-HTR-106 is 0N.

5.2.63 SET the Heat Trace Cabinet Heater VTP-HTR-104 thermostat temperature to below the ambient temperature.

5.2.64 VERIFY Heat Trace Cabinet Heater VTP-HTR-104 is OFF.

5.2.65 SET the Intrinsic Barrier Cabinet Heater VTP-HTR-106 thermostat temperature to below the ambient temperature.

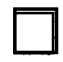

5.2.66 VERIFY Intrinsic Barrier Cabinet Heater VTP-HTR-106 is OFF.

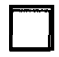

5.2.67 POSITION the Heat Trace Cabinet Selector Switch "CAB HEAT/COOL" VTP-HS-104 to OFF.

0




\subsection{POWER SYSTEM CHECK (Continued)}

\section{WARNING}

Energized circuits and lead are contained inside the cabinet.

observe Appropriate electrical precautions. Comply with WHC-CM-1-

10, WKS-15, ELECTRICAL WORK SAFETY.

5.2.68 USING a DMM, VERIFY $120 \mathrm{~V}$ at the Mini Power Zone Cabinet (VTP-PNL101) Receptacle.

5.2.69 USING a DMM, VERIFY $120 \mathrm{~V}$ at the Alarm Cabinet (VTP-ENCL-107) Receptacle.

NOTE - Wilkerson indicators for DPTs should be indicating zero.

5.2.70 VERIFY the Wilkerson indicators are illuminated by visual inspection. Fill in the following table.

\begin{tabular}{|c|c|c|c|}
\hline Indicators & $\begin{array}{l}\text { OK } \\
(\checkmark)\end{array}$ & Indicators & $\begin{array}{l}0 \mathrm{~K} \\
(\mathrm{~V})\end{array}$ \\
\hline VTP -PDI - 177 & & VTP $L I-185$ & \\
\hline VTP-PDI- 178 & & VTP $11-205$ & \\
\hline VTP-PDI 180 & & VTP $T 1-179$ & \\
\hline VTP-PDI -182 & & VTP,$T /-176$ & \\
\hline VTP POI - 181 & & VTP-TI 183 & \\
\hline VTP $-F-184$ & & & \\
\hline
\end{tabular}

5.2.71 VERIFY the Green FAN OFF indicating light (located on the door of the Exhauster Control Cabinet VTP-CP-105) is ILLUMINATED: 


\section{TANK FARM ACCEPTANCE TEST PROCEDURE}

\subsection{POWER SYSTEM CHECK (Continued)}

5.2.72 VERIFY the digital readouts on the following six DPTs.

\begin{tabular}{|l|l|l|l|}
\hline Transmitter & $\begin{array}{l}\text { OK } \\
\text { (V) }\end{array}$ & Transmitter & $\begin{array}{l}\text { OK } \\
(V)\end{array}$ \\
\hline VTP-DPT-177 (Heater) & & VTP-DPT $182\left(2^{\text {nd }}\right.$ HEPA $)$ & \\
\hline VTP-DPT-178 (Pre-fi)ter) & & VTP-DPT-181 $\left(1^{\text {st }} \& 2^{\text {nd }}\right.$ HEPA $)$ & \\
\hline VTP-DPT-180 $\left(1^{\text {st }}\right.$ HEPA $)$ & & VTP-FI-184 $($ Stack $)$ & \\
\hline
\end{tabular}

5.2.73 POSITION the following 120V circuit breakers (located at MPZ Cabinet) to OFF.

- Circuit Breaker \#2 (Future Flammable Gas Monitor) SPARE

- Circuit Breaker \#8 (Air Monitor Vac Pumps / Cabinet Heater \& Fan)

5.2.74 Test Director SHALL VERIFY that section 5.2 is COMPLETE by SIGNING below.

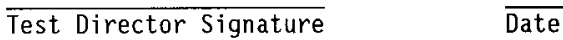




\section{TANK FARM ACCEPTANCE TEST PROCEDURE}

\subsection{FILTER \#1 DP INTERLOCK/ALARM CHECK (Transmitter Range 0-10")}

5.6.1 ENSURE the High, Low and Equalizing valve on VTP-DPT-180's three valve manifold are CLOSED or OPEN as indicated below:

\begin{tabular}{|l|c|c|c|c|c|c|}
\hline DPT & $\begin{array}{c}\text { Valve } \\
\text { HI }\end{array}$ & $\begin{array}{c}\text { open } \\
(v)\end{array}$ & $\begin{array}{c}\text { valve \# } \\
L\end{array}$ & $\begin{array}{c}\text { Open } \\
(v)\end{array}$ & $\begin{array}{c}\text { valve \# } \\
\text { EQUAL }\end{array}$ & $\begin{array}{c}\text { (losed } \\
(V)\end{array}$ \\
\hline VTP-PDT-180 & \begin{tabular}{c} 
V-179 \\
\hline
\end{tabular} & & $v-144$ & & $v-145$ & \\
\hline
\end{tabular}

5.6.2 REMOVE back cover from VTP-PDT-180.

5.6.3 CONNECT a BT-200 to the transmitter VTP-PDT-180.

5.6.4 ENSURE Fan/0ff/Enable Control Selector Switch VTP-HS-103 (located on door of Exhauster Control Cabinet VTP-CP-105) is in the Enable position.

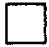

5.6.5 PRESS Fan Start Button VTP-PB-101 (located on door of Exhauster Control Cabinet VTP-(P-105).

5.6.6 WAIT for the Exhauster fan to come up to speed.

5.6.7 SET the BT-200 to test at $045.0 \%$. This is equal to 4.5 IN W.C. 


\section{TANK FARM ACCEPTANCE TEST PROCEDURE}

\subsection{FILTER \# 1 DP INTERLOCK/ALARM CHECK (Continued)}

5.6.8 VERIFY the following:

- Clear Rotating Beacon VTP-XA-101 is ILLUMINATED.

- Red FAN RUNNING light is ILLUMINATED.

- Green faN OFF light is NOT ILLUMINATED.

- Message View Displays VTP-MV-101 and VTP-MV-102 (located at Alarm Cabinet Swing Out Panel) DISPLAY "FILTER 1 DP HI".

5.6.9 RECORD the pressure indicated by the Wilkerson indicator VTP-PDI180 (located on door of Exhauster Control Cabinet VTP-CP-105).

Indicated Pressure:

5.6.10 ACKNOWLEDGE the alarm by PRESSING the 1 button, then pressing the "r" button on the Message View Display VTP-MV-101 (1ocated at Al arm Cabinet VTP-ENCL-107 Swing Out Pane1) twice. For any secondary alarms repeat this step until all alarms are cleared.

5.6.11 VERIFY Clear Rotating Beacon VTP-XA-101 is NOT ILLUMINATED.

5.6.12 VERIFY Message View Display VTP-MV-102 (located at Alarm Cabinet Swing Out Pane1) STILL DISPLAYS "FILTER 1 DP HI". Any secondary alarms that are still in alarm condition will also be indicated.

5.6.13 SET the BT-200 to test at $054.0 \%$. This is equivalent to 5.4 IN W.C. 


\section{TANK FARM ACCEPTANCE TEST PROCEDURE}

\subsection{FILTER \# 1 DP INTERLOCK/ALARM CHECK (Cont inued)}

\subsubsection{VERIFY the following:}

- Exhauster Fan VTP-EF-001 has SHUTDOWN.

- Red FAN RUNNING light is NOT ILLUMINATED.

- Green FAN OFF light is ILLUMinated.

- Clear Rotating Beacon VTP-XA-10I (located on stack supporting framing) is ILLUMINATED.

- Message View Display VTP-MV-101 (located at Alarm Cabinet Swing out Panel) DISPLAYS "FILTER 1 DP HIHI" and "FAN SHUTDOWN". Any secondary alarms that are still in alarm condition will also be indicated.

5.6.15 RECORD the pressure indicated by the Wilkerson indicator VTP-PDI180 (located on door of Exhauster Control Cabinet VTP-CP-105).

Indicated Pressure:

5.6.16 ACKNOWLEDGE the alarm by PRESSING the "1" button, then pressing the " $\rightarrow$ " button on the Message View Display VTP-MV-101 (located at Alarm Cabinet VTP-ENCL-107 Swing Out Panel) twice. For any secondary alarms repeat this step until all alarms are cleared

5.6.17 VERIFY Clear Rotating Beacon VTP-XA-101 is NOT ILLUMINATED. 


\section{TANK FARM ACCEPTANCE TEST PROCEDURE}

\subsection{FILTER \#1 DP INTERLOCK/ALARM CHECK (Cont inued)}

5.6.18 VERIFY Message View Display VTP-MV-102 (located at Alarm Cabinet Swing out Panel) STILL DISPLAYS "FILTER 1 DP HIHI". Note: Any secondary alarms that are still in alarm condition will also be indicated.

5.6.19 CLEAR the BT-200 test setting.

5.6.20 FORCE the rate of change logic.

5.6.21 PRESS Fan Start Button PB-101 (located on door of Exhauster Control Cabinet VTP-CP-105).

5.6.22 WAIT for the Exhauster fan to come up to speed.

5.6.23 SET the BT-200 to test at $000.1 \%$. This is equivalent to approximately 0.1 IN W.G. 
5.6 FILTER \# 1 DP INTERLOCK/ALARM CHECK (Continued)

5.6.24 VERIFY the following:

- Exhauster Fan VTP-EF-001 has SHUTDOWN after 10 seconds.

- Red fan running light is not illuminated.

- Green fan off light is illuminated.

- Clear Rotating Beacon VTP-XA-101 (located on stack supporting framing) is ILLUMINATED.

- Message View Display VTP-MV-101 and VTP-MV-102 (located at Alarm Cabinet Swing Out Panel) DISPLAYS "FILTER 1 DP LO" and "FAN SHUTDOWN". Any secondary alarms that are still in alarm condition will also be indicated.

5.6.25 ACKNOWLEDGE the alarm by PRESSING the " 1 " button, then pressing the " $"$ " button on the Message View Display VTP-MV-101 (located at Alarm Cabinet VTP-ENCL-107 Swing Out Panel) twice. For any secondary alarms repeat this step until all alarms are cleared

5.6.26 VERIFY Clear Rotating Beacon VTP-XA-101 is NOT ILLUMINATED.

5.6.27 VERIFY Message View Display VTP-MV-102 (located at Alarm Cabinet Swing out Panel) STILL DISPLAYS "FILTER 1 DP L0". Note: Any secondary alarms that are still in alarm condition will also be indicated.

5.6.28 CLEAR the BT-200 test setting. 


\subsection{FILTER \# 1 DP INTERLOCK/ALARM CHECK (Continued)}

5.6.29 REMOVE force on the rate of change logic.

5.6.30 PRESS the Fan Start Button PB-101 (located on the door of Exhauster Control Cabinet VTP-CP-105).

5.6.31 WAIT 2 minutes for the fan to come up to speed.

5.6.32 RECORD VTP-PDT-180 reading.

Reading:

5.6.33 SET the BT-200 to test at 0.5 IN W.C. less then the value recorded in the previous step from transmitter VTP-PDT-180.

5.6.34 RECORD the BT-200 setting.

Setting: 
5.6 FILTER \# 1 DP INTERLOCK/ALARM CHECK (Continued)

5.6.35 VERIFY the following:

- Clear rotating beacon VTP-XA-101 is ILLUMINATED.

- Red fan running light is NOT ILLUMINATED.

- Green fan off light is Illuminated.

- Exhauster fan VTP-EF-001 has shutdown.

- Message view display VTP-MV-101 (located at alarm cabinet swing out pane1) DISPLAYS "Filter I DP ROC". Any secondary alarms that are still in alarm condition will also be indicated.

5.6.36 ACKNOWLEDGE the alarm by PRESSING the " 1 " button, then pressing the " $\$$ " button on the Message View Display VTP-MV-101 (located at A1 arm Cabinet VTP-ENCL-107 Swing Out Pane1) twice. For any secondary alarms repeat this step until all alarms are cleared

5.6.37 VERIFY Clear Rotating Beacon VTP-XA-101 is NOT ILLUMINATED.

5.6.38 VERIFY Message View Display VTP-MV-102 (located at Alarm Cabinet Swing Out Pane1) STILL DISPLAYS "FILTER 1 DP HIHI". Note: Any secondary alarms that are still in alarm condition will also be indicated.

5.6.39 DISCONNECT BT-200 from transmitter VTP-PDT- 180 .

5.6.40 REPLACE back cover on transmitter VTP-PDT-180. 


\subsection{FILTER \# 1 DP INTERLOCK/ALARM CHECK (Continued)}

5.6.41 Test Director SHALL VERIFY that section 5.6 is COMPLETE by SIGNING below.

$\overline{\text { Test Director Signature }}$

Date 
5.7 FILTER \#2 DP INTERLOCK/ALARM CHECK (Transmitter Range 0-6")

5.7.1 ENSURE the High, Low and Equalizing valves on VTP-DPT-182 three valve manifold are CLOSED or OPEN as indicated below:

\begin{tabular}{|c|c|c|c|c|c|c|}
\hline DPT & Valve \# HI & $\begin{array}{c}\text { OPEN } \\
(V)\end{array}$ & Valve \# LO & $\begin{array}{c}\text { OPEN } \\
(V)\end{array}$ & $\begin{array}{c}\text { Valve \# } \\
\text { EQUAL }\end{array}$ & $\begin{array}{c}\text { CLOSEO } \\
(V)\end{array}$ \\
\hline VTP-PDT-182 & V-149 & & V-150 & & V-151 & \\
\hline
\end{tabular}

5.7.2 REMOVE back cover from the transmitter VTP-PDT-182.

5.7.3 CONNECT a BT-200 to the transmitter VTP-PDT-182.

5.7.4 ENSURE Fan/Off/Enable Control Selector Switch VTP-HS-103 (located on door of Exhauster Control Cabinet VTP-CP-105) is in the Enable position.

5.7.5 PRESS Fan Start Button PB-101 (located on door of Exhauster Control Cabinet VTP-CP-105).

5.7.6 WAIT for the Exhauster fan to come up to speed.

5.7.7 SET BT-200 to test at 053.4\%. This is equivalent to 3.2 IN W.C.

0




\subsection{FILTER \#2 DP INTERLOCK/ALARM CHECK (Cont inued)}

\subsubsection{VERIFY the following:}

- Clear Rotating Beacon VTP-XA-101 is ILLUMINATED.

- Red Fan RUNNing light is ILLUMinated.

- Green FAN OFF light is NOT ILLUMINATED.

- Message View Displays VTP-MV-101 and VTP-MV-102 (located at Alarm Cabinet Swing Out Panel) DISPLAY "FILTER 2 DP HI".

5.7.9 RECORD value from Wilkerson indicator VTP-PDI-182 (located on door of Exhauster Control Cabinet VTP-CP-105).

READING:

IN W.C.

5.7.10 ACKNOWLEDGE the alarm by PRESSING the "1" button, then pressing the " $\rightarrow$ "button on the Message View Display VTP-MV-101 (located at Alarm Cabinet VTP-ENCL-107 Swing Out Panel) twice. For any secondary alarms repeat this step until all alarms are cleared.

5.7.11 VERIFY Clear Rotating Beacon VTP-XA-101 is NOT ILLUMINATED.

5.7.12 VERIFY Message View Display VTP-MV-102 (located at Alarm Cabinet Swing out Panel) STILL DISPLAYS "FILTER 2 DP HI".

5.7.13 SET the BT-200 to test at 061.7\%. This is equivalent to 3.7 IN W.C. 
5.7 FILTER \#2 DP INTERLOCK/ALARM CHECK (Continued)

5.7.14 VERIFY the following:

- Exhauster Fan VTP-EF-00l has SHUTDOWN.

- Red FAN RUNNING light is NOT ILLUMINATED.

- Green FAN OFF light is Illuminated.

- Clear Rotating Beacon VTP-XA-101 (located on stack supporting framing) is ILLUMINATED.

- Message View Display VTP-MV-101 (located at Alarm Cabinet Swing Out Pane1) DISPLAYS "FILTER 2 DP HIHI" and "FAN SHUTDOWN". Any secondary alarms that are still in alarm condition will also be indicated.

5.7.15 RECORD value from Wilkerson indicator VTP-PDI-182 (located on door of Exhauster Control Cabinet VTP-CP-105).

READING :

IN W.C.

5.7.16 ACKNOWLEDGE the alarm by PRESSING the "1" button, then pressing the " + " button on the Message View Display VTP-MV-101 (located at Alarm Cabinet VTP-ENCL-107 Swing Out Panel) twice. For any secondary alarms repeat this step until all alarms are cleared.

5.7.17 VERIFY Clear Rotating Beacon VTP-XA-101 is NOT ILLUMINATED.

5.7.18 VERIFY Message View Display VTP-MV-102 (located at Alarm Cabinet Swing Out Panel) STILL DISPLAYS "FILTER 2 DP HIHI". Any secondary alarms that are still in alarm condition will also be indicated. 


\subsection{FILTER \# 2 DP INTERLOCK/ALARM CHECK (Cont inued)}

5.7.19 CLEAR the BT-200 test setting.

5.7.20 FORCE the rate of change logic.

5.7.21 PRESS Fan Start Button VTP-PB-101 (located on door of Exhauster Control Cabinet VTP-CP-105).

5.7.22 WAIT for the Exhauster fan to come up to speed.

5.7.23 SET the BT-200 to test at $001.6 \%$. This is equivalent to 0.1 IN W.C.

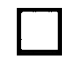

5.7.24 VERIFY the following:

- Exhauster Fan VTP-EF-001 has SHUTDOWN after 10 seconds.

- Red Fan RUNNing light is NOT ILlUMinAtEd.

- Green fan OFF light is Illuminated.

- Clear Rotating Beacon VTP-XA-101 (located on stack supporting framing) is ILLUMINATED.

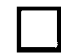

- Message View Display VTP-MV-101 and VIP-MV-102 (located at Alarm Cabinet Swing Out Panel) DISPLAYS "FILTER 1 DP LO" and "FAN SHUTDOWN". Any secondary alarms that are still in alarm condition will also be indicated. 


\subsection{FILTER \#2 DP INTERLOCK/ALARM CHECK (Cont inued)}

5.7.25 ACKNOWLEDGE the alarm by PRESSING the "1" button, then PRESSING the " $ه$ " button on the Message View Display VTP-MV-101 (located at Alarm Cabinet VTP-ENCL-107 Swing Out Pane1) twice. For any secondary alarms repeat this step until all alarms are cleared.

5.7.26 VERIFY Clear Rotating Beacon VTP-XA-101 is NOT ILLUMINATED.

5.7.27 VERIFY Message View Display VTP-MV-102 (located at Alarm Cabinet Swing Out Pane1) STILL DISPLAYS "FILTER 2 DP L0" and "FAN SHUTDOWN". Any secondary alarms that are still in alarm condition will also be indicated.

5.7.28 CLEAR the BT-200 test setting.

5.7.29 REMOVE force on the rate of change logic.

5.7.30 PRESS the Fan Start Button PB-101 (located on the door of Exhauster Control Cabinet VTP-CP-105).

5.7.31 WAIT 2 minutes for the fan to come up to speed.

5.7.32 RECORD VTP-PDT-182 reading.

Reading:

5.7.33 SET the BT-200 to test at 0.5 IN W.C. less then the value recorded in the previous step from transmitter VTP-PDT-182.

5.7.34 RECORD the BT-200 setting.

Setting:

0




\subsection{FILTER \#2 DP INTERLOCK/ALARM CHECK (Continued)}

5.7.35 VERIFY the following:

- Clear rotating beacon VTP-XA-101 is ILLUMINATED.

- Red fan running light is NOT ILLUMINATED.

- Green fan off light is Illuminated.

- Exhauster fan VTP-EF-001 has shutdown.

- Message view display VTP-MV-101 (located at alarm cabinet swing out panel) DISPLAYS "Filter 2 DP ROC". Any secondary alarms that are still in alarm condition will also be indicated.

5.7.36 ACKNOWLEDGE the alarm by PRESSING the " 1 " button, then pressing the "↔" button on the Message View Display VTP-MV-101 (located at Alarm Cabinet VTP-ENCL-107 Swing Out Panel) twice. For any secondary alarms repeat this step until all alarms are cleared

5.7.37 VERIFY Clear Rotating Beacon VTP-XA-101 is NOT ILLUMINATED.

5.7.38 VERIFY Message View Display VTP-MV-102 (located at Alarm Cabinet Swing out Panel) STILL DISPLAYS "FILTER 1 DP HIHI". Note: Any secondary alarms that are still in alarm condition will also be indicated.

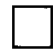

5.7.39 RESET BT-200.

5.7.40 DISCONNECT BT-200 from transmitter VTP-PDT-182. 


\subsection{FILTER \#2 DP INTERLOCK/ALARM CHECK (Continued)}

5.7.41 REPLACE back cover on transmitter VTP-PDT-182.

5.7.42 Test Director SHALL VERIFY that section 5.7 is COMPLETE by SIGNING below.

$\overline{\text { Test Director Signature }} \quad \overline{\text { Date }}$


5.8 FILTER \# 1 \& \#2 DP INTERLOCK/ALARM CHECK (Transmitter Range 06")

5.8.1 ENSURE the High, Low and Equalizing valves on VTP-DPT-181 three valve manifold are CLOSED or OPEN as indicated below:

\begin{tabular}{|c|c|c|c|c|c|c|}
\hline DPT & $\begin{array}{c}\text { valve } \\
H I\end{array}$ & $\begin{array}{c}\text { OPEN } \\
(V)\end{array}$ & $\begin{array}{c}\text { Valve } \\
\text { LO }\end{array}$ & $\begin{array}{c}\text { OPEN } \\
(V)\end{array}$ & $\begin{array}{c}\text { Valve \# } \\
\text { EQUAL }\end{array}$ & $\begin{array}{c}\text { CLOSED } \\
(f)\end{array}$ \\
\hline VTP-PDT-181 & V-146 & & V-147 & & V-148 & \\
\hline
\end{tabular}

5.8.2 REMOVE back cover on the transmitter VTP-PDT-181.

5.8.3 CONNECT a BT-200 to the transmitter VTP-PDT-181.

5.8.4 ENSURE Fan/Off/Enable Control Selector Switch VTP-HS-103 (1ocated on door of Exhauster Control Cabinet VTP-CP-105) is in the Enable position.

5.8.5 PRESS Fan Start Button VTP-PB-101 (located on door of Exhauster Control Cabinet VTP-CP-105).

5.8.6 WAIT for the Exhauster fan to come up to speed.

5.8.7 SET the BT-200 to test at $090.0 \%$. This is equivalent to 5.4 IN W.C.

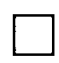




\subsection{FILTER \# 1 \& \#2 DP INTERLOCK/ALARM CHECK (Cont inued)}

5.8.8 VERIFY the following:

- Exhauster Fan VTP-EF-001 has SHUTDOWN.

- Red FAN RUNNING 1 ight is NOT ILLUMINATED.

- Green FAN OFF light is ILLUMINATED.

- Clear Rotating Beacon VTP-XA-101 (located on stack supporting framing) is ILLUMINATED.

- Message View Display VTP-MV-101 (located at Alarm Cabinet Swing Out Panel) DISPLAYS "FILTER 1 \& 2 DP HIHI" and "FAN SHUTDOWN". Any secondary alarms that are still in alarm condition will also be indicated.

- Message View Display VTP-MV-102 (located at Alarm Cabinet Swing Out Pane1) DISPLAYS "FILTER 1 \& 2 DP HIHI" secondary alarms that are still in alarm condition will also be indicated.

5.8.9 RECORD value from WiTkerson indicator VTP-PDI-182 (1ocated on door of Exhauster Control Cabinet VTP-CP-105).

READING :

IN W.C.

5.8.10 ACKNOWLEDGE the alarm by PRESSING the "1" button, then pressing the "+" button on the Message View Display VTP-MV-101 (located at Alarm Cabinet VTP-ENCL-107 Swing Out Pane1) twice. For any secondary alarms repeat this step until all alarms are cleared.

5.8.11 VERIFY Clear Rotating Beacon VTP-XA-101 is NOT ILLUMINATED. 
5.8 FILTER \# 1 \& \# 2 DP INTERLOCK/ALARM CHECK (Continued)

5.8.12 VERIFY Message View Display VTP-MV-102 (located at Alarm Cabinet Swing Out Pane1) STILL DISPLAYS "FILTER 182 DP HIHI". Any secondary alarms that are still in alarm condition will also be indicated.

5.8.13 CLEAR the BT-200 test setting.

5.8.14 FORCE the rate of change logic.

5.8.15 PRESS Fan Start Button VTP-PB-101 (1ocated on door of Exhauster Control Cabinet VTP-CP-105).

5.8.16 WAIT for the Exhauster fan to come up to speed.

5.8.17 SET the BT-200 to test at $001.6 \%$. This is equivalent to approximately 0.1 IN W.C. 


\subsection{FILTER \#1 \& \#2 DP INTERLOCK/ALARM CHECK (Continued)}

\subsubsection{VERIFY the following:}

- Exhauster Fan VTP-EF-001 has SHUTDOWN after 10 seconds.

- Red FAN RUNNing 1 ight is NOT ILLUMINATED.

- Green fan OFF light is Illuminated.

- Clear Rotating Beacon VTP-XA-101 (located on stack supporting framing) is ILLUMINATED.

- Message View Display VTP-MV-101 (located at Alarm Cabinet Swing Out Pane1) DISPLAYS "FILTER 1\&2 DP L0" and "FAN SHUTDOWN". Any secondary alarms that are still in alarm condition will also be indicated.

- Message View Display VTP-MV-102 (located at Alarm Cabinet Swing Out Pane1) DISPLAYS "FILTER 182 DP 10". Any secondary alarms that are still in alarm condition will also be indicated.

5.8.19 ACKNOWLEDGE the alarm by PRESSING the "1" button, then three times "w" button on the Message View Display VTP-MV-101 (located at Alarm Cabinet VTP-ENCL-107 Swing Out Pane1). For any secondary alarms repeat this step until all alarms are cleared.

5.8.20 VERIFY Clear Rotating Beacon VTP-XA-101 is NOT ILLUMINATED.

5.8.21 VERIFY Message View Display VTP-MV-102 (1ocated at Alarm Cabinet Swing Out Pane1) STILL DISPLAYS "FILTER 1\&2 DP L0" and "FAN SHUTDOWN". Any secondary alarms that are still in alarm condition will also be indicated. 


\subsection{FILTER \# 1 \& \#2 DP INTERLOCK/ALARM CHECK (Continued)}

5.8.22 CLEAR the BT-200 test setting.

5.8.23 REMOVE force on the rate of change logic.

5.8.24 PRESS the Fan Start Button PB-101 (located on the door of Exhauster Control Cabinet VTP-CP-105).

5.8.25 WAIT approximately 2 minutes for the fan to come up to speed.

5.8.26 RECORD VTP-PDT-181 reading.

Reading:

5.8.27 SET the BT-200 to test at $<0.5$ IN W.G. of VTP-PDT-181 reading.

5.8.28 RECORD the BT-200 setting.

Setting: 


\subsection{FILTER \# 1 \& \#2 DP INTERLOCK/ALARM CHECK (Continued)}

5.8.29 VERIFY the following:

- Clear rotating beacon VTP-XA-101 is ILLUMINATED.

- $\quad$ Red fan running light is NOT ILLUMINATED.

- Green fan off light is ILLUMINATED.

- Exhauster fan VTP-EF-001 has shutdown.

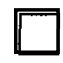

- Message view display VTP-MV-101 (located at alarm cabinet swing out pane1) DISPLAYS "Filter 1 \& 2 DP ROC". Any secondary alarms that are still in alarm condition will also be indicated.

5.8.30 ACKNOWLEDGE the alarm by PRESSING the "1" button, then pressing the " + "button on the Message View Display VTP-MV-101 (10cated at Alarm Cabinet VTP-ENCL-107 Swing Out Panel) twice. For any secondary alarms repeat this step until all alarms are cleared

5.8.31 VERIFY Clear Rotating Beacon VTP-XA-101 is NOT ILLUMINATED.

5.8.32 VERIFY Message View Display VTP-MV-102 (located at Alarm Cabinet Swing Out Panel) STILL DISPLAYS "FILTER 1 DP HIHI". Note: Any secondary alarms that are still in alarm condition will also be indicated.

5.8.33 DISCONNECT BT-200 from transmitter VTP-PDT- 181 .

5.8.34 REPLACE back cover on transmitter VTP-PDT-181. 


\section{TANK FARM ACCEPTANCE TEST PROCEDURE}

\subsection{FILTER \# 1 \& \#2 DP INTERLOCK/ALARM CHECK (Cont inued)}

5.8.35 Test Director SHALL VERIFY that section 5.8 is COMPLETE by SIGNING below.

$\overline{\text { Test Director Signature }}$

$\overline{\text { Date }}$ 


\subsection{PREFILTER DP INTERLOCK/ALARM CHECK (Transmitter Range 0-2")}

5.9.1 ENSURE the High, Low and Equalizing valve on VTP-DPT-178 three valve manifold are CLOSED or OPEN as indicated below:

\begin{tabular}{|c|c|c|c|c|c|c|}
\hline BPT & $\begin{array}{c}\text { Valve } \# \\
\text { HI }\end{array}$ & $\begin{array}{l}\text { OPEN } \\
(V)\end{array}$ & $\begin{array}{c}\text { Valve } \# \\
\text { LO }\end{array}$ & $\begin{array}{l}\text { OPEN } \\
\text { (1) }\end{array}$ & $\begin{array}{c}\text { VaTve \# } \\
\text { EQUAL }\end{array}$ & $\begin{array}{c}\text { CLOSED } \\
(1)\end{array}$ \\
\hline VTP-PDT- 178 & $V+140$ & & $v-141$ & & $V-142$ & \\
\hline
\end{tabular}

5.9.2 REMOVE back cover on transmitter VTP-PDT-178.

5.9.3 CONNECT a BT-200 to the transmitter VTP-PDT-178.

5.9.4 ENSURE Fan/Off/Enable Control Selector Switch VTP-HS-103 (located on door of Exhauster Control Cabinet VTP-CP-105) is in the Enable position.

5.9.5 PRESS Fan Start Button VTP-PB-101 (located on door of Exhauster Control Cabinet VTP-CP-105).

5.9.6 WAIT for the Exhauster fan to come up to speed.

5.9.7 SET the BT-200 to test at $050.0 \%$. This is equivalent to 1.0 IN W.C. 
5.9 PREFILTER DP INTERLOCK/ALARM CHECK (Cont inued)

5.9.8 VERIFY the following:

- Clear Rotating Beacon VTP-XA-101 is ILLUMINATED.

- Red fan Running light is Illuminated.

- Green fan OfF 1ight is NOT Illuminated.

- Message View Display VTP-MV-101 (located at Alarm Cabinet Swing Out Pane1) DISPLAYS "PRE-FILTER DP HI".

5.9.9 RECORD value from Wilkerson indicator VTP-PDI-178 (located on door of Exhauster Control Cabinet VTP-CP-105).

READING:

IN W.C.

5.9.10 ACKNOWLEDGE the alarm by PRESSING the " 1 " button, then pressing the " + " button on the Message View Display VTP-MV-101 (located at Al arm Cabinet VTP-ENCL-107 Swing Out Pane1) twice. For any secondary alarms repeat this step until all alarms are cleared.

5.9.11 VERIFY Clear Rotating Beacon VTP-XA-101 is NOT ILLUMINATED.

5.9.12 VERIFY Message View Display VTP-MV-102 (located at Alarm Cabinet Swing Out Panel) STILL DISPLAYS "PRE-FILTER DP HI".

5.9.13 DISCONNECT BT-200.

5.9.14 REPLACE back cover on transmitter VTP-PDT-178.

\begin{tabular}{|c|c|c|c|}
\hline Usage Type & Document No. \\
CONTINOUS USE & HNF-SD-WM-ATP-198 & Rev/Mod & Page \\
& 0 & 68 \\
\hline
\end{tabular}




\subsection{PREFILTER DP INTERLOCK/ALARM CHECK (Continued)}

5.9.15 Test Director SHALL VERIFY that section 5.9 is COMPLETE by SIGNING below.

$\overline{\text { Test Director Signature }}$

$\overline{\text { Date }}$ 


\subsection{STACK FLOW INTERLOCK/ALARM CHECK}

NOTE: This test must be performed when exhaust temperature is at $100^{\circ} \mathrm{F}$.

5.10.1 PRESS Fan Start Button VTP-PB-101 (located on door of Exhauster Control Cabinet VTP-CP-105).

5.10.2 WAIT for the Exhauster fan to come up to speed.

5.10.3 FORCE fan input to 500 CFM.

5.10.4 VERIFY fan operation continues.

5.10.5 RECORD value indicated by Wilkerson indicator VTP-FT-184 (located on door of Exhauster Control Cabinet VTP-(P-105).

READING :

5.10.6 VERIFY Wilkerson indicator VTP-FT-184 (located on door of Exhauster Control Cabinet VTP-CP-105) is READING within a range of 495 CFM and 505 CFM.

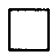

5.10.7 FORCE fan input to 530 CFM. 


\subsection{STACK FLOW INTERLOCK/ALARM CHECK (Continued)}

5.10.8 PERFORM the following:

- VERIFY Clear Rotating Beacon VTP-XA-101 (1ocated on stack supporting framing) is ILLUMINATED.

- RECORD value indicated on Wilkerson indicator VTP-FI-184 (located on door of Exhauster Control Cabinet VTP-CP-105), corresponding to transmitter FT-184.

READING:

- VERIFY Wilkerson indicator VTP-FI-184 (located on door of Exhauster Control Cabinet VTP-(P-105), corresponding to transmitter FT-184, is READING a flow rate within a range of 525 CFM and 535 CFM.

- VerIfY Message View Display MV-101 and MV-102 (located at Alarm Cabinet Swing Out Panel) DISPLAYS "STACK FLOW HI".

5.10.9 ACKNOWLEDGE the alarm by PRESSIMG the " 1 " button, then pressing the " $\rightarrow$ " button on the Message View Display VTP-MV-101 (located at Alarm Cabinet VTP-ENCL-107 Swing Out Panel) twice. For any secondary alarms repeat this step until all alarms are cleared.

5.10.10 VERIFY Clear Rotating Beacon VTP-XA-101 is NOT ILLUMINATED.

5.10.11 VERIFY Message View Display VTP-MV-101 (located at Alarm Cabinet Swing Out Pane1) CLEARS alarm message.

5.10.12 CLEAR force.

5.10.13 PRESS Fan Start Button VTP-PB-101 (located on door of Exhauster Control Cabinet VTP-CP-105). 


\subsection{STACK FLOW INTERLOCK/ALARM CHECK (Continued)}

5.10.14 WAIT for the Exhauster fan to come up to speed.

5.10.15 FORCE fan input to 230 CFM.

5.10.16 RECORD the value indicated on the Wilkerson indicator VTP-FI-184

(1ocated on door of Exhauster Control Cabinet VTP-CP-105), corresponding to transmitter FT-184.

READING:

5.10.17 VERIFY the Wilkerson indicator VTP-FI-184 (located on door of Exhauster Control Cabinet VTP-CP-105), corresponding to transmitter FT-184, is READING a flow rate within a range of 225 CFM and 235 CFM.

5.10.18 VERIFY the Clear Rotating Beacon VTP-XA-101 (located on stack supporting framing) is ILLUMINATED.

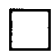

5.10.19 VERIFY the following:

- Clear rotating beacon VTP-XA-101 is ILLUMINATED.

- $\quad$ Red fan running light is NOT ILLUMINATED.

- Green fan off light is ILLUMINATED.

- Exhauster fan VTP-EF-001 has shutdown.

- Message View Display VTP-MV-101 and VTP-MV-102 (located at Alarm Cabinet Swing Out Panel) DISPLAYS "STACK FLOW L0". 


\subsection{STACK FLOW INTERLOCK/ALARM CHECK (Continued)}

5.10.20 ACKNOWLEDGE the alarm by PRESSING the " 1 " button, then PRESSING the "+" button on the Message View Display VTP + MV-101 (located at Alarm Cabinet VTP-ENCL-107 Swing Out Pane1) twice. For any secondary alarms repeat this step until all alarms are cleared.

5.10.21 VERIFY Clear Rotating Beacon VTP-XA-101 is NOT ILLUMINATED.

5.10.22 VERIFY Message View Display VTP-MV-101 (located at Alarm Cabinet Swing out Pane1) CLEARS al arm message.

5.10.23 REMOVE aొl fan input forces.

5.10.24 Test Director SHALL VERIFY that section 5.10 is COMPLETE by SIGNING below.

Test Director Signature

Date 


\subsection{SEAL POT INTERLOCK/ALARM CHECK}

5.11.1 ENSURE Seal Pot Drain Valve VTP-V-160 is in the CLOSED position.

5.11.2 ENSURE Seal Pot Overflow Drain Line Outlet Valve VTP-V-161 is in the $25 \pm 10 \%$ OPEN position.

5.11.3 REMOVE Seal Pot fill cap at VTP-V-159.

5.11.4 OPEN Seal Pot fill inlet valve VTP-V-159.

5.11.5 Add water to Seal Pot reservoir UNTIL the seal pot reservoir is $50 \pm 5 \%$ ful1.

5.11.6 RECORD the Seal Pot Level from the Wilkerson Indicator VTP-LI-185. READING :

5.11.7 ENSURE Fan/Off/Enable Control Selector Switch VTP-HS-103 (located on door of Exhauster Control Cabinet VTP-CP-105) is in the Enable position.

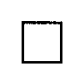

5.11.8 PRESS Fan Start Button VTP-PB-101 (located on door of Exhauster Control Cabinet VTP-CP-105).

5.11.9 WAIT for the Exhauster fan to come up to speed.

5.11.10 ADD water to the Seal Pot UNTIL the rotating beacon is ILLUMINATED, OR UNTIL a seal pot level of $90 \%$ is indicated on LI105.

5.11.11 VERIFY that the Seal Pot Level Wilkerson Indicator VTP-LI-185 is INDICATING a liquid level corresponding to $80 \%$ FULL. 


\subsection{SEAL POT INTERLOCK/ALARM CHECK (Continued)}

5.11.12 VERIFY the following:

- Message View Display VTP-MV-101 and VTP-MV-102 (located at Alarm Cabinet Swing out Panel) DISPLAYS "SEAL POT HI" and "FAN SHUTDOWN".

d (2)

- The exhaust Fan VTP-EF-001 has shutdown.

- Red fan running light is NOT ILLUMINATED.

- Green fan off light is ILLUMINATED.

- Clear Rotating Beacon VTP-XA-101 is ILLUMINATED.

5.11.13 ACKNOWLEDGE the alarm by PRESSING the "1" button, then PRESSING the "ه" button on the Message View Display VTP-MV-101 (located at Alarm Cabinet VTP-ENCL-107 Swing Out Pane1) twice. For any secondary alarms repeat this step until a11 alarms are cleared.

5.11.14 VERIFY Clear Rotating Beacon VTP-XA-101 is NOT ILLUMINATED.

5.11.15 OPEN the Seal Pot drain valve VTP-V-160.

5.11.16 SLOWLY DRAIN the Seal Pot until the alarm message clears.

5.11.17 CLOSE the Seal Pot drain valve VTP-V-160. 


\subsection{SEAL POT INTERLOCK/ALARM CHECK (Continued)}

5.11.18 VERIFY Message View Display VTP-MV-102 (1ocated at Alarm Cabinet Swing out Panel) CLEARS alarm message at an approximate liquid leve 1 that is LESS THAN $75 \%$ FULL, as indicated by the SEAL POT LEVEL Wilkerson indicator VTP-LI-185.

5.11.19 PRESS Fan Start Button VTP-PB-101 (10cated on door of Exhauster Control Cabinet VTP-CP-105).

5.11.20 WAIT for the Exhauster fan to come up to speed.

5.11.21 CONTINUALLY DRAIN the Seal Pot until rotating beacon ILLUMINATES again, QUICKLY CLOSE the Seal Pot drain valve VTP-V-160.

5.11.22 VERIFY the following:

- Clear rotating beacon VTP-XA-101 is ILLUMINATED.

- $\quad$ Red fan running light is NOT ILLUMINATED.

- Green fan off light is ILLUMINATED.

- Exhauster fan VTP-EF-001 has shutdown.

5.11.23 RECORD the Seal Pot Level indicated by Wilkerson Indicator VTP-LI185.

READING :

5.11.24 VERIFY the Seal Pot Level Wi1kerson Indicator VTP-LI-185 INDICATES a liquid level of $30 \pm 5 \%$ FULL.

\begin{tabular}{|c|c|c|c|}
\hline $\begin{array}{l}\text { Usage Type } \\
\text { CONTINOUS USE }\end{array}$ & $\begin{array}{l}\text { Document Ho. } \\
\text { HNF SD-WM-ATP } 198\end{array}$ & $\begin{array}{l}\text { Rev/Mod } \\
0\end{array}$ & Page \\
\hline
\end{tabular}




\subsection{SEAL POT INTERLOCK/ALARM CHECK (Continued)}

5.11.25 VERIFY that the Message View Display VTP-MV-101 and VTP-MV-102 DISPLAYS "SEAL POT L0".

5.11.26 ACKNOWLEDGE the alarm by PRESSING the "1" button, then pressing the "w" button on the Message View Display VTP-MV-101 (located at Alarm Cabinet VTP-ENCL-107 Swing Out Panel) twice. For any secondary alarms repeat this step until all alarms are cleared.

5.11.27 VERIFY Clear Rotating Beacon VTP-XA-101 is NOT ILLUMINATED.

5.11.28 VERIFY Message View Display VTP-MV-102 (located at Alarm Cabinet Swing out Pane1) STILL DISPLAYS "SEAL POT LO".

5.11.29 ADD water to the seal pot reservoir UNTIL the reservoir is $50 \pm 5 \%$ FULL.

5.11.30 VERIFY Message View Display VTP-MV-102 (located at Alarm Cabinet Swing out Panel) message has cleared.

5.11.31 CLOSE Seal Pot fill inlet valve VTP-V-159.

5.11.32 REINSTALL seal pot fill cap.

5.11.33 Test Director SHALL VERIFY that section 5.11 is COMPLETE by SIGNING below.

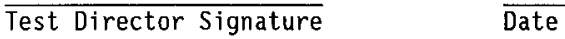




\subsection{GLYCOL INTERLOCK/ALARM CHECK}

5.12.1 ENSURE G1ycol Reservoir Tank VTP-TK-001 drain valve VTP-V-204 is closed.

5.12.2 ENSURE Glycol Heater Piping isolation valves are open.

\begin{tabular}{|l|l|l|l|}
\hline $\begin{array}{l}\text { Valve Number } \\
\text { VTP-V-135 Plenum Inlet }\end{array}$ & Open & $\begin{array}{l}\text { Valve Number } \\
\text { (V) }\end{array}$ \\
\hline $\begin{array}{l}\text { VTP-V-201 Gl ycol Jank - 202 Glycol Heater } \\
\text { inlet }\end{array}$ & & $\begin{array}{l}\text { VTP-V-203 Glycol Heater } \\
\text { outlet }\end{array}$ & \\
\hline
\end{tabular}

5.12.3 POSITION Circuit Breaker \#3 (located at MPZ Cabinet) to OFF.

5.12.4 DISCONNECT probe leads from transmitter VTP-LT-205.

5.12.5 CONNECT Drexelbrook C-Box to transmitter probe side of transmitter VTP-LT-205.

5.12.6 CONNECT 3-terminal wire to capacitance unit.

5.12.7 SET range switch to NORMAL.

5.12.8 CONNECT Drexelbrook C-Box meter leads in series with VTP-LT-205 OUTPUT.

5.12.9 CONNECT terminal wire to meter.

5.12.10 SET meter range to 4-20 mA. 


\subsection{GLYCOL INTERLOCK/ALARM CHECK (Continued)}

5.12.11 PRESS meter ONLY button ON (down).

5.12.12 POSITION Circuit Breaker \#3 (Tocated at MPZ Cabinet) to ON.

5.12.13 SET Vernier Dial to 14.5 Picofarads ( $p f)$. This is equivalent to 4 mA.

5.12.14 INCREASE Vernier Dial to $46.5 \mathrm{pf}$. This is equal to approximately $60 \%$ volume (13.6 mA).

5.12.15 ENSURE circuit breaker \#6 (SLC Control Circuit, Module 8 / VFD001 ) is ON (located in the MPZ cabinet VTP-DP-101).

5.12.16 POSITION Glycol Circulation Pump Control Switch VTP-HS-102 to ON (located on door of Exhauster Control Cabinet VTP-CP-105).

\subsubsection{VERIFY/RECORD the following:}

- Glycol Level Wilkerson Indicator VTP-LI-205 displays a readout corresponding to a $60 \%$ level.

READING :

- Glycol Circulation Pump is OPERATING by LISTENING to and/or FEELING the pump.

Glycol System has no leaks.

5.12.18 POSITION G1ycol Pump Control Switch VTP-HS-102 to OFF (located on door of Exhauster Control Cabinet VTP-CP-105). 


\subsection{GLYCOL INTERLOCK/ALARM CHECK (Continued)}

5.12.19 ACKNOWLEDGE the PUMP OFF alarm by PRESSING the "1" button, then PRESSING the "+" button on the Message View Display VTP-MV-101 (located at Alarm Cabinet VTP-ENCL-107 Swing Out Panel) twice. For any secondary alarms repeat this step until all alarms are cleared.

5.12.20 REMOVE the thermostat cover on top of Glycol Heater VTP-HTR-001.

5.12.21 ENSURE the Heater Thermostat is set to $190^{\circ} \mathrm{F}$.

5.12.22 REPLACE the thermostat cover of G1ycol Heater VTP-HTR-001.

5.12.23 POSITION the Glycol Heater Disconnect Switch VTP-DS-201 to ON.

5.12.24 POSITION Glycol Circulation Pump Control Switch VTP-HS-102 to ON (located on door of Exhauster Control Cabinet VTP-CP-105). 


\subsection{GLYCOL INTERLOCK/ALARM CHECK (Cont inued)}

\section{WARNING}

Energized circuits and lead are contained inside the cabinet.

Observe Appropriate electrical precautions. Comply with WHC-CM-1-

10, WKS-15, ELECTRICAL WORK SAFETY.

5.12.25 VERIFY the G1ycol Heater has STARTED by USING the DMM at the GTycol Heater Contactor VTP-CON-206 (located at Heat Trace Cabinet VTP-ENCL-104) and PERFORMING the following:

5.12.25.1 RECORD voltage between Terminal $\mathrm{Tl}$ and Terminal $\mathrm{T} 2$.

$$
\text { READING: }
$$

5.12.25.2 VERIFY there is a voltage between Terminal T1 and Terminal T2.

5.12.25.3 RECORD voltage between Terminal T1 and Terminal T3. READING :

5.12.25.4 VERIFY there is a voltage between Terminal $\mathrm{Tl}$ and Terminal T3.

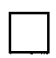

5.12.25.5 RECORD voltage between Terminal T2 and Terminal T3.

READING:

5.12.25.6 VERIFY there is a voltage between Terminal T2 and Terminal T3.

5.12.26 POSITION the Glycol Heater Disconnect Switch VTP-DS-201 to OFF.

5.12.27 REDUCE the impedance to simulate $50 \%$ Volume $38.75 \mathrm{pf}$ (12 $\mathrm{mA}$ ) on the Glycol Liquid Level Transmitter VTP-LT-205. 


\subsection{GLYCOL INTERLOCK/ALARM CHECK (Cont inued)}

5.12.28 VERIFY the following:

- Clear rotating beacon VTP-XA-101 is ILLUMINATED.

- Glycol Heater has SHUTDOWN by OBSERVING that the Glycol Heater contactor VTP-CON-206 (10cated at Control Cabinet VTP-CP-105) is OPEN.

- Glycol Circulation Pump VTP-P-001 has SHUTDOWN by LISTENING to and/or FEELING the pump.

- Message Display VTP-MV-101 and VTP-MV-102 DISPLAYS "GLYCOL LEVEL LO".

5.12.29 RECORD the liquid level indication on the Wilkerson liquid level indicator VTP-LI-205.

READING :

5.12.30 ACKNOWLEDGE the alarm by PRESSING the "1" button, then PRESSING the "ه" button on the Message View Display VTP-MV-101 (located at Alarm Cabinet VTP-ENCL-107 Swing Out Panel) twice. For any secondary alarms repeat this step until all alarms are cleared.

5.12.31 VERIFY Clear Rotating Beacon VTP-XA-101 is NOT ILLUMINATED.

5.12.32 VERIFY Message View Display VTP-MV-101 (located at Alarm Cabinet Swing Out Panel) CLEARS alarm message.

5.12.33 VERIFY Message View Display VTP-MV-102 (located at Alarm Cabinet Swing Out Pane1) DISPLAYS "GLYCOL LEVEL LO" al arm.

5.12.34 POSITION Circuit Breaker \#3 (located at MPZ Cabinet) to OFF.

\begin{tabular}{|c|c|c|c|}
\hline $\begin{array}{l}\text { Usage Type } \\
\text { CONTINOUS USE }\end{array}$ & $\begin{array}{l}\text { Document No } \\
\text { HNF-SD-WM-ATP-198 }\end{array}$ & $\begin{array}{l}\text { Rev/Mod } \\
\qquad 0\end{array}$ & Page \\
\hline
\end{tabular}




\section{TANK FARM ACCEPTANCE TEST PROCEDURE}

\subsection{GLYCOL INTERLOCK/ALARM CHECK (Cont inued)}

5.12.35 DISCONNECT the DrexelBrook Calibrator from the Glycol Liquid Level Transmitter VTP-LT-205.

5.12.36 RECONNECT probe leads to transmitter VTP-LT-205.

5.12.37 Test Director SHALL VERIFY that section 5.12 is COMPLETE by SIGNING below.

$\overline{\text { Test Director Signature }} \overline{\text { Date }}$ 


\subsection{GLYCOL SYSTEM LEAK CHECK}

This test verifies that the glycol heater, reservoir, and associated piping do not leak to the environment. A visual leak check will be performed followed by a pressure decay test. The following cautions apply to this test section:

\section{CAUTION}

The system under test shall be pressurized by means of a manifold consisting of a pressure gauge, pressure relief valve, isolation valve, pressure source, and a pressure release valve.

- All system components shall have pressure ratings equal to or greater than the system test pressure.

- The test gauge shall have a dial graduated from zero over a range that in no case shall be less than 1-1/2 or more than four times the intended maximum pressure.

- The pressure relief valve shall be set to operate at a pressure that does not exceed $110 \%$ of the test pressure. The relief valve pressure setting shall be verified by use of a calibrated test instrument.

- The flow capacity of the pressure relief valve shall not be less than $125 \%$ of the flow capacity of the pressurizing device.

- A means for immediately shutting off and releasing the pressure shall be provided to prevent damage if the relief valve or other critical system components fail to operate in case of overpressurization.

- All test equipment shall be maintained in good operating condition and be capable of withstanding test pressures.

The Material Safety Data Sheet for Glycol should be reviewed prior to working with that chemical. 


\subsection{GLYCOL SYSTEM LEAK CHECK (Cont inued)}

5.13.1 OPEN Glycol Heater Piping isolation valves.

\begin{tabular}{|l|l|l|l|}
\hline VaT Ve Number & Open & Valve Number & $\begin{array}{l}\text { Open } \\
\text { (f) }\end{array}$ \\
\hline VTP-V-135 Plenum Inlet & & $\begin{array}{l}\text { VTP-V-203 Glycol Heater } \\
\text { outlet }\end{array}$ & \\
\hline $\begin{array}{l}\text { VTP-V-201 Glycol Tank } \\
\text { outlet }\end{array}$ & $\begin{array}{l}\text { VTP-V-204 Glycol Tank } \\
\text { Drain }\end{array}$ & \\
\hline $\begin{array}{l}\text { VTP-V-202 Glycol Heater } \\
\text { inlet }\end{array}$ & & & \\
\hline
\end{tabular}

5.13.2 REMOVE the fill cap from the heater reservoir.

5.13.3 CONNECT the pressure supply manifold to the reservoir fill port.

5.13.4 SLOWLY PRESSURIZE the heater reservoir and piping to $10 \mathrm{psig.}$

5.13.5 VISUALLY INSPECT for leaks indicated by localized wetting. Perform this step for a minimum of 15 minutes.

5.13.6 REPAIR any leaks per Test Director direction.

5.13.7 ENSURE the heater reservoir and piping are pressurized to $10 \pm 2$ psig.

5.13.8 ISOLATE the pressure source by closing the manifold isolation valve. 


\subsection{GLYCOL SYSTEM LEAK CHECK (Cont inued)}

5.13.9 RECORD the initial pressure and time.

PRESSURE (psig)

INITIAL:

FINAL:

5.13 .10

WAIT 10 minutes.

5.13.11 RECORD the final pressure and time.

5.13.12 VERIFY there was no pressure drop during the 10 minute time period.

5.13.13 RELIEVE pressure from the system by slowly opening the manifold release valve.

5.13.14 DISCONNECT and REMOVE the pressure supply and manifold.

5.13.15 Test Director SHALL VERIFY that section 5.13 is COMPLETE by SIGNING below.

Test Director Signature

Date

5.13.16 QC Inspector SHALL VERIFY that section 5.13 is COMPLETE by SIGNING below.

QC Inspector Signature

Date 


\subsection{THERMOCOUPLE INTERLOCK/ALARM CHECK}

5.14.1 REMOVE thermocouple TE-179 from the thermowe11.

5.14.2 POSITION the Glycol Heater Disconnect Switch VTP-DS-201 to ON.

5.14.3 ENSURE circuit breaker \#6 (SLC Control Circuit, Module 8 / VFD001) is ON (located in the MPZ cabinet VTP-DP-101).

5.14.4 POSITION Glycol Circulation Pump Control Switch VTP-HS-102 to ON (located on door of Exhauster Control Cabinet VTP-CP-105).

5.14.5 VERIFY Glycol Heater has STARTED by OBSERVING that the G7ycol Heater Contactor VTP-CON-206 (located at Control Cabinet VTP-CP105) is CLOSED.

5.14.6 HEAT thermocouple TE-179 with a Hot Air Gun UNTIL the Wilkerson Indicator VTP-TI-179 is indicating $>200^{\circ} \mathrm{F}$.

5.14.7 VERIFY the following:

- Clear Rotating Beacon VTP-XA-101 (located on stack support framing) is ILLUMINATED.

- Message View Display VTP-MV-101 and VTP-MV-102 (1ocated at Alarm Cabinet Swing Out Panel) DISPLAYS "HEATER AIR TEMPERATURE HI".

- Glycol Heater has SHUTDOWN by OBSERVING that the Glycol Heater Contactor VTP-CON-206 (located at the Control Cabinet VTP-CP-105) is OPEN. 


\subsection{THERMOCOUPLE INTERLOCK/ALARM CHECK (Cont inued)}

5.14.8 ACKNOWLEDGE the alarm by PRESSING the " 1 " button, then PRESSING the " + " button on the Message View Display VTP-MV-10l (located at Alarm Cabinet VTP-ENCL-107 Swing Out Panel) twice. For any secondary alarms repeat this step until all alarms are cleared.

5.14.9 VERIFY Clear Rotating Beacon VTP-XA-101 is NOT ILLUMINATED.

5.14.10 VERIFY Message View Display VTP-MV-101 (located at Alarm Cabinet Swing Out Pane1) CLEARS alarm message.

5.14.11 ALLOW thermocouple TE-179 to cool to $<100^{\circ} \mathrm{F}$.

5.14.12 PLACE thermocouple TE-179 in a cup of ice.

5.14.13 VERIFY the following AFTER the thermocouple indicates $\angle 40^{\circ} \mathrm{F}$ on Wilkerson Indicator VTP-TI-179:

- Clear Rotating Beacon VTP-XA-101 (located on stack supporting framing) is ILLUMINATED.

- RECORD indication on Wilkerson indicator TI-179 (located on door of Exhauster Control Cabinet VTP-CP-105) corresponding to VTP-TE-176.

READING:

- Message View Display VTP-MV-101 and VTP-MV-102 (located at Alarm Cabinet Swing Out Panel) DISPLAYS "HEATER TEMPERATURE L0".

5.14.14 ACKNOWLEDGE the alarm by PRESSING the " 1 " button, then PRESSING the "ه" button on the Message View Display VTP-MV-101 (located at Alarm Cabinet VTP-ENCL-107 Swing Out Pane1) twice. For any secondary alarms repeat this step until all alarms are cleared. 


\subsection{THERMOCOUPLE INTERLOCK/ALARM CHECK (Continued)}

5.14.15 VERIFY Clear Rotating Beacon VTP-XA-101 is NOT ILLUMINATED.

5.14.16 VERIFY Message View Display VTP-MV-102 (located at Alarm Cabinet Swing Out Pane1) DISPLAYS alarm message.

5.14.17 POSITION Circuit Breaker \#3 (located at MPZ Cabinet) to OFF.

5.14.18 REPLACE Thermocouple TE-179 into the thermowel1.

5.14.19 Test Director SHALL VERIFY that section 5.14 is COMPLEJE by SIGNING below. 


\subsection{GLYCOL HEATER TEST}

5.15.1 VERIFY Glycol Reservoir Tank VTP-TK-001 is approximately $60 \pm 5 \%$ full by observing level sight glass VTP-LG-201.

5.15.2 ENSURE the Glycol Heater Piping isolation valves are OPEN or CLOSED as indicated below:

\begin{tabular}{|c|c|c|c|}
\hline Valve Number & $\begin{array}{l}\text { Open } \\
(1)\end{array}$ & Valve Number & Open \\
\hline VTP V 135 Plenum Inlet & & $\begin{array}{l}\text { VTP V } 202 \text { Gl ycol Heater } \\
\text { inlet }\end{array}$ & \\
\hline \multirow[t]{2}{*}{$\begin{array}{l}\text { VTP V } 201 \text { Glycol Tank } \\
\text { out let }\end{array}$} & & $\begin{array}{l}\text { VTP V } 203 \text { Glycol Heater } \\
\text { out } 7 \text { et }\end{array}$ & \\
\hline & $\begin{array}{l}\text { CLOSED } \\
(\sqrt{ })\end{array}$ & & \\
\hline VTP-V-204 Drain Valve & & & \\
\hline
\end{tabular}

5.15.3 POSITION circuit breaker \#6 (1ocated in the MPZ cabinet VTP-DP101) to OFF.

5.15.4 REMOVE the thermostat cover on top of Glycol Heater VTP-HTR-001.

5.15.5 ENSURE the heater thermostat is set to $190^{\circ} \mathrm{F}$.

5.15.6 REPLACE the thermostat cover on top of Glycol Heater VTP-HTR-001.

5.15.7 POSITION circuit breaker \#6 (1ocated in the MPZ cabinet VTP-DP101) to $0 N$.

5.15.8 POSITION the EXHAUSTER FAN MOTOR DISCONNECT SWITCH VTP-DS-102 to ON. 


\subsection{GLYCOL HEATER TEST (Continued)}

5.15.9 PRESS Fan Start Button VTP-PB-101 (Located on door of Exhauster Control Cabinet VTP-CP-105) to turn ON Exhauster Fan VTP-EF-001.

5.15.10 POSITION the Glycol Heater Disconnect Switch VTP-DS-201 to ON.

5.15.11 POSITION G]ycol Circulation Pump Control Switch VTP-HS-102 to ON (located on door of Exhauster Control Cabinet VTP-CP-105) and record initial values for time, inlet temperature, and outlet temperature below.

\begin{tabular}{|l|l|l|}
\hline & INITIAL & FINAL \\
\hline Time and Date & & \\
\hline $\begin{array}{l}\text { Inlet temperature }\left({ }^{\circ} \mathrm{F}\right), \\
\text { VTP-T1-176 }\end{array}$ & & \\
\hline $\begin{array}{l}\text { Out Tet temperature }\left({ }^{\circ} \mathrm{F}\right), \\
\text { VTP-TI-179 }\end{array}$ & & \\
\hline
\end{tabular}

5.15.12 CONTINUE exhauster operation until the airflow temperature indicated by thermocouple VTP-TI- 179 has stabilized to vary $\pm 2^{\circ} \mathrm{F}$ or less.

5.15.13 RECORD final values for time, inlet temperature, and outlet temperature.

5.15.14 VERIFY the final out let temperature is AT LEAST $20^{\circ} \mathrm{F}$ greater then the final inlet temperature.

5.15.15 POSITION the Glycol Heater Disconnect Switch VTP-DS-201 to OFF.

5.15.16 POSITION Glycol Circulation Pump Control Switch VTP-HS-102 to Off (located on door of Exhauster Control Cabinet VTP-CM-105). 


\title{
TANK FARM ACCEPTANCE TEST PROCEDURE
}

\subsection{GLYCOL HEATER TEST (Continued)}

5.15.17 POSITION the EXHAUSTER FAN MOTOR DISCONNECT SWITCH VTP-DS-102 to OFF.

5.15.18 Test Director SHALL VERIFY that section 5.15 is COMPLETE by SIGNING below.

\author{
$\overline{\text { Test Director Signature }}$
}

$\overline{\text { Date }}$


DATA SHEET 1 - LEAKAgE RATE CALCULATION (This page may be reproduced as necessary) DATE:

\section{TEST \# :}

\begin{tabular}{|c|c|c|}
\hline & INITIAL & FINAL \\
\hline Time & $\mathrm{ti}=$ & $t f=$ \\
\hline Pressure (psig) & $\begin{aligned} \mathrm{Pi} & =\ldots \text { IN W.C./ } 27.7 \\
& =\end{aligned}$ & $\begin{aligned} P f & =\quad \text { IN W.C. / } 27.7 \\
& =\end{aligned}$ \\
\hline Barometric pr (IN Hg) & $\begin{aligned} \mathrm{BPi} & =\longrightarrow \mathrm{IN} \mathrm{Hg} \times 0.491 \\
& =\end{aligned}$ & $\begin{aligned} \mathrm{BPf} & =\ldots \text { IN Hg } \times 0.491 \\
& =\end{aligned}$ \\
\hline Duct pr (psfa) & $\begin{aligned} D P i & =(P i+8 p i)(144) \\
& =\end{aligned}$ & $\begin{aligned} D P i & =(P i+B p i)(144) \\
& =\end{aligned}$ \\
\hline Temperature $\left({ }^{\circ} \mathrm{R}\right)$ & $\begin{aligned} T i & =\ldots \\
& =\end{aligned}$ & $\begin{aligned} T f & =\ldots \\
& =\end{aligned}$ \\
\hline
\end{tabular}

Test Volume: $\quad V=$ cubic feet

Gas constant: $\quad R=53.35 \mathrm{ft} 7 \mathrm{~b} /(7 \mathrm{~b} * \operatorname{deg} R)$

Test Duration: $\quad \Delta t=(t f-t i)=[$ minutes

$Q=(D P i / T i-D P f / T f) V /(R \times \Delta t \times 0.075)=$ SCFM

$Q$ is the Average total leak rate per ASME N510-1989, Section 6.5.3.9, in standard $\mathrm{ft}^{3} / \mathrm{min}$ (SCFM).

$\mathrm{L}_{\mathrm{s}}=$ Allowable Leak Rate $=0.3$ SCFM

$\overline{\text { Test Director Signature }} \overline{\text { Date }} \overline{\text { QC Signature }} \overline{\text { Date }}$

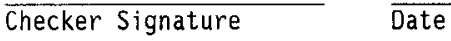


DATA SHEET 2 - LEAKAGE RATE CALCULATION (This page may be reproduced as necessary) DATE: TEST \#:

\begin{tabular}{|c|c|c|}
\hline & INITIAL & FINAL \\
\hline Time & $\mathrm{ti}=$ & $t f=$ \\
\hline Pressure (psig) & $\begin{aligned} \mathrm{Pi} & =\text { IN W.C./ } 27.7 \\
& =\end{aligned}$ & $\begin{aligned} \text { Pf } & =\text { IN W.C. / } 27.7 \\
& =\end{aligned}$ \\
\hline Barometric pr (IN Hg) & $\begin{aligned} \mathrm{BPi} & =\ldots \text { IN Hg } \times 0.491 \\
& =\end{aligned}$ & $\begin{aligned} \mathrm{BPf} & =\ldots \text { IN Hg } \times 0.491 \\
& =\end{aligned}$ \\
\hline Duct $p r$ (psfa) & $\begin{aligned} D P i & =(P i+B p i)(144) \\
& =\end{aligned}$ & $\begin{aligned} D P i & =(P i+B p i)(144) \\
& =\end{aligned}$ \\
\hline Temperature $\left({ }^{\circ} \mathrm{R}\right)$ & $\begin{aligned} T i & ={ }^{\circ} \mathrm{F}+460 \\
& =\end{aligned}$ & $\begin{aligned} T f & ={ }^{\circ} \mathrm{F}+460 \\
& =\end{aligned}$ \\
\hline
\end{tabular}

Test Volume:

$v=$ cubic feet

Gas constant: $\quad R=53.35 \mathrm{ft} 1 \mathrm{~b} /(1 \mathrm{~b} *$ degR $)$

Test Duration: $\Delta t=(t f-t i)=$ minutes $Q=(\mathrm{DPi} / \mathrm{Ti}-\mathrm{DPf} / \mathrm{Tf}) \mathrm{V} /(\mathrm{R} \times \Delta t \times 0.075)=$ SCFM

$Q$ is the Average total leak rate per ASME N510-1989, Section 6.5.3.9, in standard $\mathrm{ft}^{3} / \mathrm{min}$ (SCFM).

$L_{s}=$ Allowable Leak Rate $=0.3$ SCFM

$\overline{\text { Test Director Signature }} \overline{\text { Date }} \overline{\text { QC Signature }} \overline{\text { Date }}$

$\overline{\text { Checker Signature }} \overline{\text { Date }}$ 


\section{ATP EXCEPTION LOG}

This page may be reproduced as necessary PAGE of

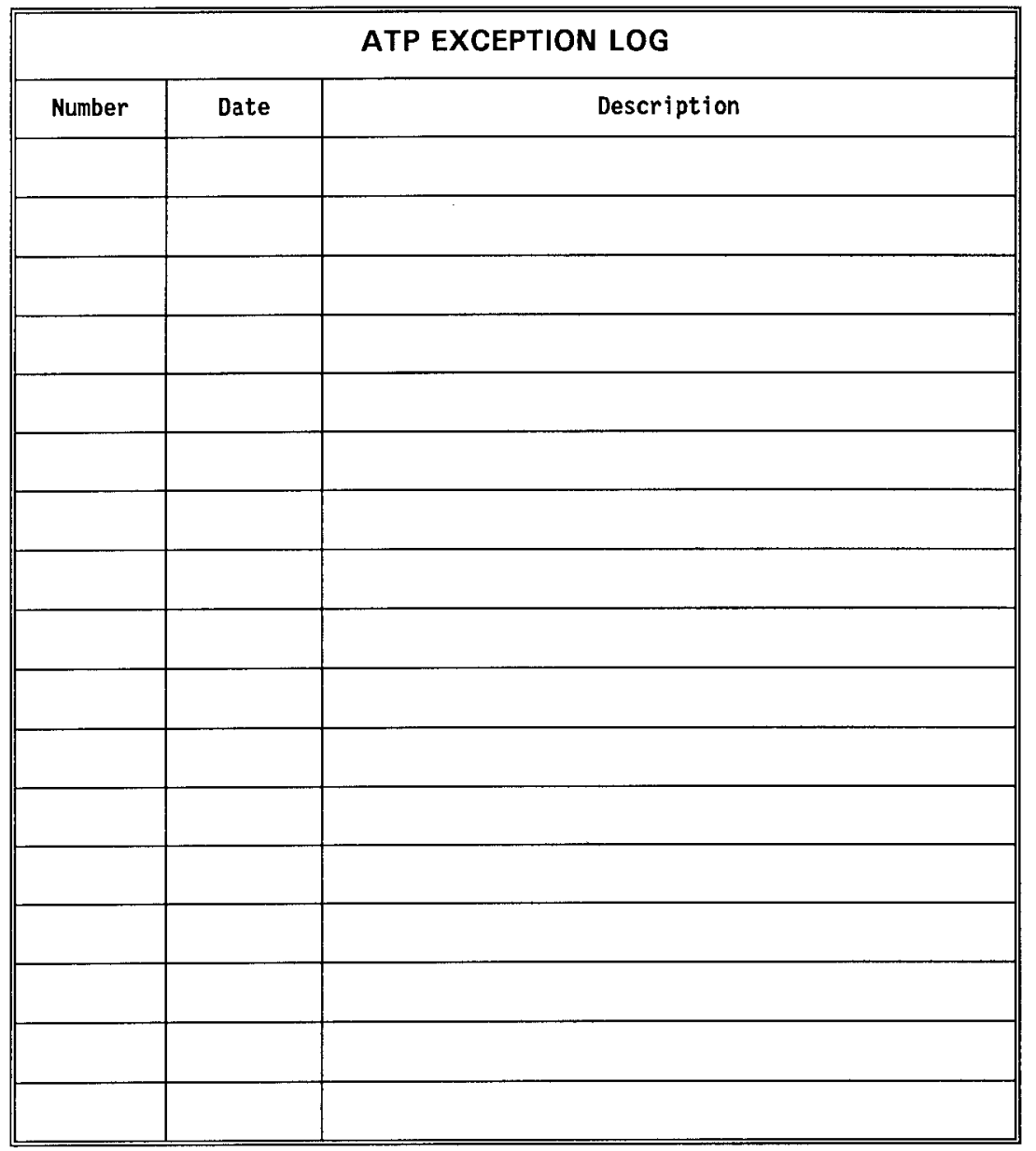




\section{ATP EXCEPTION RECORD}

This page may be reproduced as necessary.

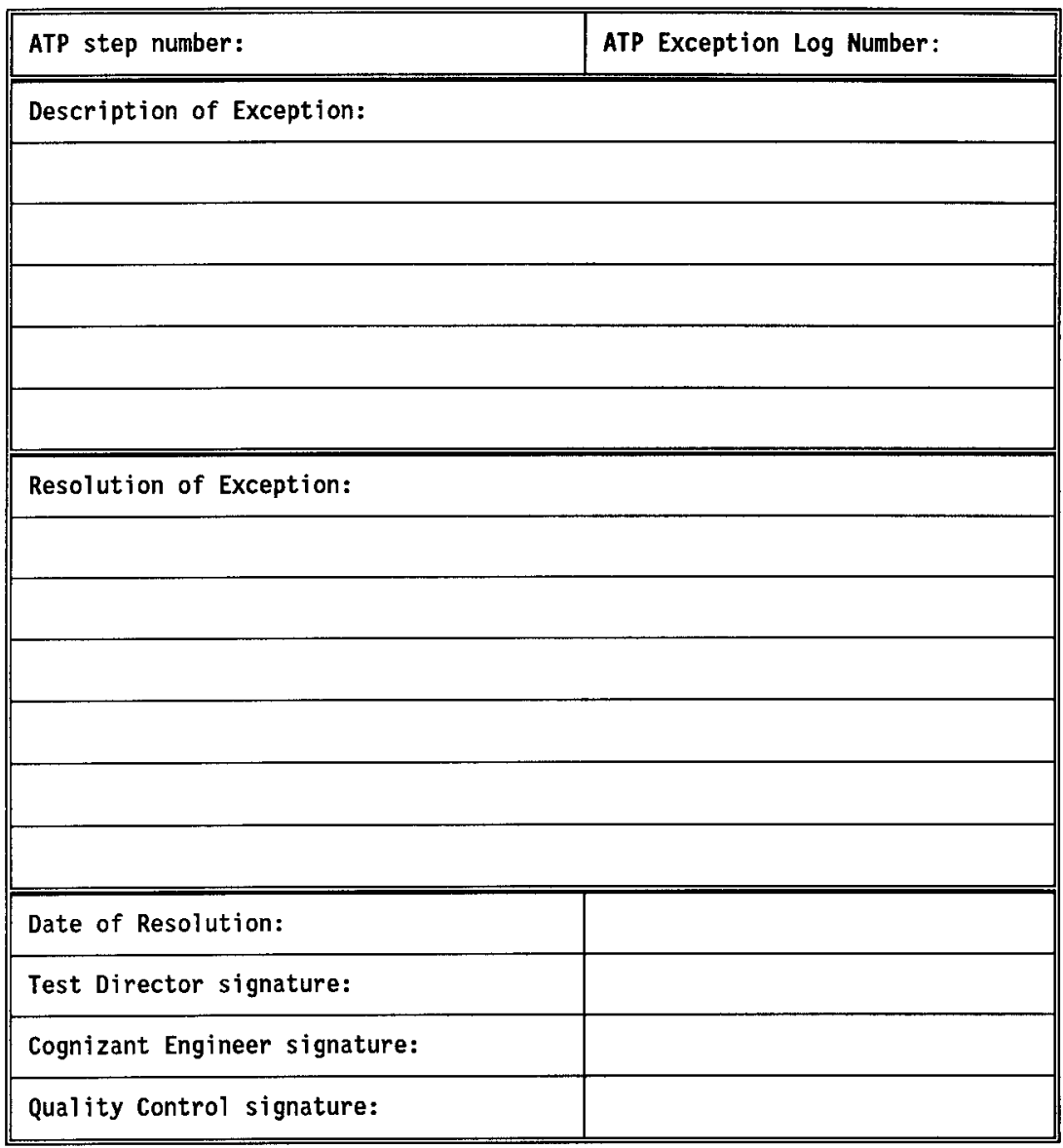

